\title{
An ethics perspective on Transcranial Magnetic Stimulation (TMS) and human neuromodulation
}

\author{
Judy Illes ${ }^{\mathrm{a}, \mathrm{b}, *}$, Marisa Gallo ${ }^{\mathrm{a}}$ and Matthew P. Kirschen ${ }^{\mathrm{a}, \mathrm{b}, \mathrm{c}}$

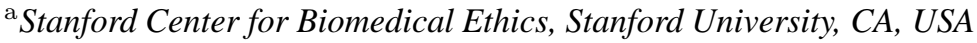 \\ ${ }^{\mathrm{b}}$ Department of Radiology, Stanford University, CA, USA \\ ${ }^{\mathrm{c}}$ Program in Neuroscience, Stanford University, CA, USA
}

\begin{abstract}
This paper concerns the ethics of human neuromodulation using transcranial magnetic stimulation (TMS). We examine the challenges of modulating the brain with TMS through the research ethics lens and in clinical medicine for treating frank pathology, primarily in psychiatric diseases. We also consider contemporary issues raised in the neuroethics literature about managing unexpected findings, and relate these to TMS and to other frontier neurotechnology that is becoming openly available in the public domain. We argue that safety and informed consent are of paramount importance for TMS, but that personal values and sociocultural factors must also be considered when examining the promise of this technology and applications that ought to be highlighted for extra precautions.
\end{abstract}

\section{The dynamic evolution of TMS research}

Transcranial magnetic stimulation (TMS) involves a powerful and rapidly changing electrical current transmitted through a coil that is placed on the scalp. It produces a magnetic field that passes unimpeded through the skull and induces a weaker electrical current in the brain [109] that transiently disrupts neural circuits at the stimulation site. The growing body of literature on TMS (Fig. 1) suggests that TMS offers several advantages over other non-invasive neuroimaging techniques in the study of normal neural functioning. Techniques like functional magnetic resonance imaging (fMRI), positron emission tomography (PET), magnetoencephalography (MEG) and electroencephalography (EEG) rely on correlations to establish brainbehavior relationships. Functional MRI, for exam-

*Corresponding author: Judy Illes, Ph.D., Senior Research Scholar, Director, Program in Neuroethics, Stanford Center for Biomedical Ethics, and Department of Radiology, Stanford, CA 94305-5748, USA. Tel.: +1 650724 6393; Fax: +1 650725 6131; E-mail: illes@stanford.edu. ple, correlates changes in hemodynamic signal with cognitive behavior. TMS, on the other hand, characterizes behavioral changes with selective disruption of normal neural signaling, revealing neural structures necessary for normal behavioral and cognitive functions. Compared to patient lesion studies - that is, studying patients with strokes or tumors - TMS has some advantages since compensatory mechanisms and functional rewiring over time can obscure understanding of the discrete function of the originally damaged tissue. In examining fundamental issues of research ethics covered in The Belmont Report issued by the National Commission for the Protection Human Subjects in Biomedical and Behavioral Research (1979), unique issues of safety, informed consent and disclosure stand out for TMS.

\subsection{Considerations of safety}

Single-pulse TMS is thought to be extremely safe and has proven to be a valuable tool for investigating normal human neurophysiology. It has been used effectively over the past 20 years to help us gain detailed knowl- 


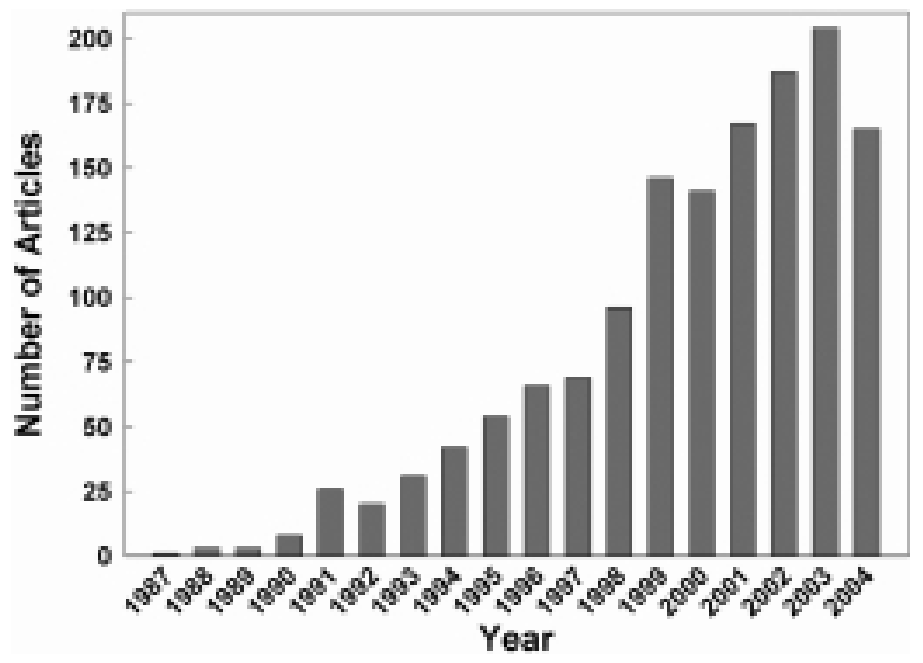

Fig. 1. Number of TMS articles published in the scientific literature per year between January 1985 and July 2004.

edge about brain-behavior relationships in such areas as motor systems $[16,19,96,111]$, visual and perceptual processing $[7,50,51,68,93]$, language $[30,33,92]$, verbal working memory $[28,53,82]$ and memory guided saccades $[15,26,35,42,59,83,85,86,91]$. Several thousand individuals have participated as normal controls in these experiments with very few adverse reactions. A small percentage of research subjects describe nonspecific symptoms like headache, nausea [99] or tinnitus after several hundred TMS pulses during a single experimental session, but no serious adverse reactions have been reported.

Enough single-pulse TMS safety studies have been conducted on both animals and humans to confidently state that there are no known short or long-term sequelae to TMS stimulation $[17,21,65,67]$. In one study, non-human primates receiving 7,000 maximum intensity single TMS pulses delivered in daily increments over thirty days demonstrated no short or long term deficits of higher cerebral functions [112]. A subsequent study administered 1,200 to 3,800 stimuli at 5$20 \mathrm{~Hz}$ over the visual cortex of eleven healthy volunteers and did not provide any evidence of pathological changes on contrast MRI or diffusion scans, demonstrating that TMS does not adversely affect the bloodbrain barrier or induce localized edema [90]. In lobectomy specimens obtained from two epileptic patients following repetitive TMS, no structural brain damage was found [61].

Compared to single-pulse TMS, repetitive TMS (rTMS) is a more powerful tool, capable of making a pronounced and possibly irreversible impact on neural functioning. It has been reported to induce seizures in a small percentage of healthy subjects $[20,43,109]$, and is therefore more likely to have longer-term effects than single pulse TMS on neural functioning. In an effort to establish safe parameters for rTMS, Pascual-Leone et al. [94] evaluated the effect of varying frequency and intensity of rTMS on cortical excitability in healthy volunteers. Adverse reactions such as headaches, visual disturbances, vertigo, weakness, and paresthesias were not experienced by subjects. Blood pressure, pulse, and ECG levels remained unchanged after stimulation. One subject experienced a seizure after three stimuli to the left motor cortex. It was later discovered that the subject had elevated prolactin levels and a family history of seizures. Other studies have also found a rise in hormones, specifically thyroid stimulating hormone (TSH), following TMS [39,103]. A second subject in Pascual-Leone et al.'s study experienced tinnitus in the left ear following rTMS, which lasted less than 30 minutes [94]. Seizures induced by TMS are estimated to occur in about 1 out of 1000 TMS and rTMS subjects [3,109].

Studies of TMS on children have identified side effects such as scalp discomfort, hand weakness, headache, neck and arm pain, and arm tingling [34,40, 80]. After surveying 28 TMS studies involving over 850 children, Gilbert et al. [40] recommended that institutional review boards classify TMS as a minimal risk procedure, despite the noted adverse effects.

In 1996, an international workshop was held to delineate the risks of rTMS and establish relevant guidelines [109]. Workshop topics covered stimulation parameters, physiological monitoring, neuropsychological monitoring, training and qualifications of rTMS op- 
erators, medical management of seizures, management of psychological consequences of seizures, and contraindications of rTMS. With a decade of experimentation in humans since Barker et al.'s [5] first description of the TMS device in 1985, and increasing uses of rTMS, the timeliness of this meeting was indisputable. Yet, for any frontier neurotechnology like rTMS whose discovery and further evolution may have a rapid farreaching impact in both research and clinical medicine, it is essential that such guidelines undergo continuous review and be as dynamic as the technology itself.

\subsection{Informed consent and disclosure}

In all biomedical research, potential benefits must outweigh the risks. As an evolving technology for the study of neural functioning, the scientific community is constantly learning more about the effects of TMS, both short and long term, on the human brain. However, given the state-of-the-art of the technology, an important question is whether enough is known about the way TMS interferes with normal brain functioning to truly obtain an informed consent from research volunteers. As we discussed above, single-pulse TMS is considered to be relatively safe. Nonetheless, many questions remain as to the nature of basic physiology of TMS-induced effects on the brain. It is evident from almost all studies that behavior on specific tasks returns to baseline post-stimulation, but it is possible that current tasks are not sensitive enough to uncover deficits that might remain, or that functions that might remain impaired (e.g., attention or speed of information processing) are not tested.

The remote effects of TMS throughout the whole brain are also still being explored. It is not yet known, for example, whether the effect of a single TMS pulse is confined to a small intended region of cortex, or if other cortical and sub-cortical structures are affected through either stray magnetic waves or magnetic waves that propagate sub-clinically through the vast neuronal interconnections of the human brain [8]. Interleaved TMS-fMRI studies $[9,12,13,88]$, although not without technical complications $[98,102]$, are currently being used to further our understanding of both direct and indirect effects of TMS, including the physical properties of TMS inside the human brain by mapping TMS fields in an MR scanner $[10,11]$ and measuring current densities using depth EEG electrodes [108].

Since it is not possible to know all of the potential short- and long-term effects associated with either single-pulse or repetitive TMS, the informed consent process must provide full disclosure of all known significant risks and acknowledge the possibility of yetunknown longitudinal effects. Such practice has precedent in the therapeutic domain, for example, where certain drugs may be prescribed to alleviate symptoms or manage diseases even though the molecular mechanisms are poorly understood. The mechanism of action of a high percentage of drugs approved by the FDA for use in the United States is listed as "unknown" in the Physicians Desk Reference (PDR), yet each of those drugs had to undergo several phases of rigorous clinical testing to ensure their safety and efficacy before obtaining FDA approval. The mechanism of how and where TMS affects the brain is becoming better understood all the time but, like pharmaceuticals, its exact mechanism of action still remains elusive.

\section{Ethical challenges for TMS in the clinical domain}

While it may be safe to stimulate healthy brain tissue, we have less information about the effects of TMS on abnormal brain tissue. This raises two major issues that we discuss here: the potential physical risks of stimulating already compromised brain tissue with TMS, and ethical challenges to using TMS clinically.

\subsection{Potential risks to functional connectivity of compromised tissue}

Some brain regions are particularly fragile and easily insulted while others are more resistant to stress and manipulation. Structures like the sensory-motor cortex have shown functional recovery after short periods of anoxia or seizure activity, whereas other structures like the hippocampus are more sensitive to stress and do not recover as quickly and might sustain more permanent damage [25,46].

Comprehensive studies have not yet been conducted looking at the effect of TMS on anatomically abnormal neural tissue, but single-pulse TMS has produced seizures in patients with predisposing brain lesions such as strokes, ALS and epilepsy [43]. The prevalence of incidental findings on research MRI scans raises the possibility of stimulating a region containing a tumor or vascular malformation unknowingly [57]. Although normal levels of neural activation have not yet been established, it is important to consider the ramifications of stimulating functionally compromised tissue. Thresholds for stimulation might vary in these tissues and we cannot dismiss the possibility that application of TMS might produce irreversible changes in connectivity and functionality. 


\subsection{Clinical challenges}

The challenges in understanding why patients may elect to undergo an innovative procedure that is still unapproved by regulatory agencies in many countries, including the Food and Drug Administration in the United States, are not particularly exceptional. We can turn to examples from the surgery and experimental therapeutics literature, and even the alternative medicine literature, to understand patient motivation, especially when no better alternative seems to exist $[18,24,62]$. Such motivations can be driven by a number of factors: the sense that doctors 'know best', that refusing to take part would upset the doctor, that there is little risk associated with participation, or that people have a moral duty to be involved in such trials [31]. In a survey given to caregivers of patients with severe Alzheimer's dementia, for example, respondents believed that entering into a clinical trial provided some chance of improving or at least maintaining the patients' condition. Caregivers who declined participation noted the potential side effects of the drugs as the primary reason [29].

Aside from such relatively established ethical challenges to any to form of innovative therapy, exceptional challenges also exist. They lie, for example, in the timing and conventions of technology transfer. As Lisanby et al. [69] have articulated, "The conventions in clinical trials on pharmaceutical agents in the treatment of psychiatric disorders do not translate perfectly to the study of TMS as a therapeutic intervention."

In TMS trial designs, unique challenges are posed by issues of standardization, clinically appropriate targets for stimulation, navigation to targets, localization and effective controls and placebos. Further, while sham TMS [69] may be standard practice for experimental control, some have questioned whether the brain is completely unaffected by the contact of the magnetic field with the scalp and accompanying clicking noise [70]. Similar debate has surfaced about whether patients are able to discern between sham and TMS treatment [14] and fully comprehend the circumstances surrounding the procedures - an issue that brings us back to earlier discussions about informed consent. Finally, the pure ethical and experimental dilemma associated with targeting a region for TMS for a psychiatric illness to which a brain location has yet to be traced is inescapable. This latter issue is especially acute given significant variability in results of clinical trials of patients with depression, a major clinical focus for TMS [36,48,63,64,69,72,77,81,87,106,110], as well as mania $[60,87]$, obsessive compulsive disorders [44,
49,73,76,97], schizophrenia [47,49,52,76,100], post traumatic stress disorder [22,45,74], Tourette Syndrome [38,84,113], Parkinson's Disease [14,71,101], epilepsy [27,78,104,105], ataxia [107], PelizaeusMerzbacher disease [89], blindness [23,95], optic atrophy [79], essential tremor [41] and migraine [2,4]. While variability in pre-existing pharmacology, gender, as well as other confounding factors such as age [32, 69] all complicate the interpretation of results, we note that compared to electroconvulsive therapy, TMS has less morbidity and appears to achieve greater precision in reaching deep brain structures $[37,75]$.

\subsection{Clinical ethics and TMS}

From the clinical ethics literature, we can borrow broad principles such as beneficence, non-maleficence, autonomy and justice [6] for evaluating TMS trials and, in the future, for approved indications. Possible harm can be mitigated by disclosure of benefit and risk, coupled with autonomous decision-making (to the extent possible in vulnerable populations). Justice, the principle that refers to access to care for all people is relevant here, naturally, but extends well beyond the TMS application alone.

We can further enrich our analysis of the suitability of therapeutic approach for the individual patient by engaging a more patient-based framework using principles of casuistry [58]. This framework is based on concrete questions that guide ethical decision-making. For example, medical indications questions focus on the nature of a patient's medical condition (diagnosis, prognosis, acuteness, reversibility), and the available treatment options (goals, probabilities of success, benefits and harms, alternatives). In the case of TMS, the extent to which a patient's condition is debilitating and is refractory to other forms of treatment weighs heavily here. Patient preference questions personalize the assessment by considering the patient's desires and goals. The preference question also takes into consideration a competency for decision-making (informed consent, mental and legal competence), a key variable as we discussed above, for patients from vulnerable populations for whom TMS may be an option. Quality of life questions consider the traditional risk/benefit assessment of the treatment in terms of the patient's likelihood to return to normal life, deficits that could occur with treatment, and whether the patient would consider life undesirable without treatment. Contextual features questions draw attention to possible sources of bias in treatment decision-making such as familial beliefs, provider 
beliefs and cultural beliefs. They take into consideration the entire context of a patient who is referred to or is contemplating TMS intervention, including personal and sociocultural views.

Even with the level of detail for assessing decisionmaking that the casuistry model provides, there is still no way - nor would it be appropriate - to compute a score of the benefits versus risks to a single patient undergoing medical treatment, especially one such as TMS for which clinical uncertainty still abounds. Yet in describing this model for clinical ethics, Jonsen et al. [55] highlight the need for such a strong methodological approach. As they have stated, and as the new neuroethics literature asserts [54,56], when ethics and practice go hand in hand truly well reasoned analyses of the ethical dilemmas can take place.

\section{Managing unexpected effects}

It is theoretically possible to get unpredictable and unintentional behavioral responses when stimulating with TMS in either of the domains we have discussed above - research and clinical applications - or when potentially used in the context of personal choice for enhancing memory, attention or cognitive performance [66]. What are the ethical concerns if such an occurrence were to happen? If TMS research continues to evolve in the same manner as functional MRI studies [55], researchers will soon be routinely stimulating regions associated with higher order cognitive functions like emotion, humor and moral judgment. However unlikely, what would happen if a person shouted an obscenity, experienced hallucinations, flashbacks or vivid dreams, or made a confession to a criminal offense during or after a TMS session? These behaviors might be associated with the targeted region or be a result of collateral stimulation from a separate, unassociated region. We did not think that unexpected findings such as clinically significant structural abnormalities would be a problem on research brain MRIs, until we looked [57]. Although unusual manifestations of TMS have yet to be reported, the increasing prevalence of rTMS and precedent set by the trends in research make their discovery a true possibility.

\section{Critical ethical thinking: From past to future neurotechnology}

Using TMS as a non-invasive brain stimulation technique to study normal brain functioning by magneti- cally interfering with neural circuits qualifies as a slippery slope. Single-pulse TMS transiently disrupts neural networks for approximately 100 milliseconds with minimal risks and very few reported complications. Repetitive TMS has a more profound effect on the brain and affects cerebral functioning for a longer period of time. How big of a leap is it from rTMS to Cyberknife [1], a non-invasive stereotactic radiosurgery system, which affects function permanently by ablation of neural tissue? Knowing that the brain will functionally reorganize itself, would it be considered ethical to study normal brain function by ablating tissue with radiosurgery? The direct effects of such studies could easily be more controlled and therefore potentially more enlightening than current patient lesion studies and TMS experiments.

Both rTMS and Cyberknife are considered noninvasive procedures and both can theoretically have long-lasting effects on neural tissue and cognitive performance. Where do we draw the line as to how much we are willing to alter healthy brain tissue before deeming it unethical? We can mechanically induce strokes, pharmacologically initiate seizures, and genetically engineer tumors to grow in a variety of lab animals, but rats, mice and even non-human primates will never demonstrate the complex response to neurological disease as humans. Are we moving towards an era of performing lesion experiments on humans that formerly resided only in the province of animal research?

While TMS may be used beneficially to map functional brain regions before tumor surgery or to help victims obliterate memories for traumatic events like violent crime, it is also worth considering the potential commercial uses of this technology. TMS applications can impair memory in a confined experimental environment, but at high enough frequency, power and duration, rTMS could more permanently disrupt or suppress memory formation, decrease sexual drive or possibly repress the desire to lie. TMS or other similar technologies have already been portrayed in film for these purposes, as in the movie Eternal Sunshine of the Spotless Mind (Focus Features, 2004) in which the protagonist seeks to have his memories of past romance erased from his mind. While advertising and sales of memory erasure technology are still absent from the open marketplace, we must consider means of ensuring that all frontier neurotechnology is reserved for responsible research and clinical use, and questionable uses kept at bay. The technology must never be used in coercive ways. We must also consider policy in the context of how our individual values come into play. For 
example, should society have unfettered access to this technology if it becomes available in the open market? What will protect consumers - especially the openly ill or covertly suffering - from marketing lures that, in the hands of non-expert TMS entrepreneurs, may be no more effective than snake oil? How should science and society evaluate rTMS as a potential replacement for pharmacological therapy that might be mandated by the judicial system for treating severe pathological antisocial behavior as an alternative to incarceration?

\section{Conclusion}

This is a time of great promise. This is also a time of great challenge, as the capabilities of frontier neurotechnology have pushed the envelope of studying and modulating brain function to new depths and new breadth. As we move ahead in our explorations with TMS, we can rely on a strong history in research and clinical ethics to guide us. However, new challenges unique to TMS will require new consideration in basic research and clinical medicine - consideration of the new lines that, collectively as members of the scientific disciplines and individually as citizens of science, we will have to decide whether or not to cross.

\section{Acknowledgements}

Supported by The Greenwall Foundation and NIH RO1 NS\#045831. Thanks to Dr. Eric Racine and Dr. Brent Solvason for their valuable input.

\section{References}

[1] J.R. Adler, Jr., S.D. Chang, M.J. Murphy, J. Doty, P. Geis and S.L. Hancock, The Cyberknife: a frameless robotic system for radiosurgery, Stereotact Funct Neurosurg 69(1-4 Pt 2) (1997), 124-128.

[2] J. Afra, A. Mascia, P. Gerard, A. Maertens de Noordhout and J. Schoenen, Interictal cortical excitability in migraine: a study using transcranial magnetic stimulation of motor and visual cortices, Ann Neurol 44(2) (1998), 209-215.

[3] R.J. Andrews, Neuroprotection trek - the next generation: neuromodulation I. Techniques - deep brain stimulation, vagus nerve stimulation, and transcranial magnetic stimulation, Ann N Y Acad Sci 993 (2003), 1-13; discussion 48-53.

[4] S.K. Aurora, B.K. Ahmad, K.M. Welch, P. Bhardhwaj and N.M. Ramadan, Transcranial magnetic stimulation confirms hyperexcitability of occipital cortex in migraine, Neurology 50(4) (1998), 1111-1114.

[5] A.T. Barker, R. Jalinous and I.L. Freeston, Non-invasive magnetic stimulation of human motor cortex, Lancet 1 (8437) (1985), 1106-1107.
[6] T. Beauchamp and J. Childress, Principles of Biomedical Ethics, (5th ed.), New York: Oxford University Press, 2001.

[7] G. Beckers and V. Homberg, Impairment of visual perception and visual short term memory scanning by transcranial magnetic stimulation of occipital cortex, Exp Brain Res 87(2) (1991), 421-432.

[8] S. Bestmann, J. Baudewig, H.R. Siebner, J.C. Rothwell and J. Frahm, Functional MRI of the immediate impact of transcranial magnetic stimulation on cortical and subcortical motor circuits, Eur J Neurosci 19(7) (2004), 1950-1962.

[9] D.E. Bohning, S. Denslow, P.A. Bohning, J.A. Walker and M.S. George, A TMS coil positioning/holding system for MR image-guided TMS interleaved with fMRI, Clin Neurophysiol 114(11) (2003), 2210-2219.

[10] D.E. Bohning, L. He, M.S. George and C.M. Epstein, Deconvolution of transcranial magnetic stimulation (TMS) maps, $J$ Neural Transm 108(1) (2001), 35-52.

[11] D.E. Bohning, A.P. Pecheny, C.M. Epstein, A.M. Speer, D.J. Vincent, W. Dannels et al., Mapping transcranial magnetic stimulation (TMS) fields in vivo with MRI, Neuroreport 8(11) (1997), 2535-2538.

[12] D.E. Bohning, A. Shastri, M.P. Lomarev, J.P. Lorberbaum, Z. Nahas and M.S. George, BOLD-fMRI response vs. transcranial magnetic stimulation (TMS) pulse-train length: testing for linearity, J Magn Reson Imaging 17(3) (2003), 279-290.

[13] D.E. Bohning, A. Shastri, E.M. Wassermann, U. Ziemann, J.P. Lorberbaum, Z. Nahas et al., BOLD-f MRI response to single-pulse transcranial magnetic stimulation (TMS), $J$ Magn Reson Imaging 11(6) (2000), 569-574.

[14] L.S. Boylan, S.L. Pullman, S.H. Lisanby, K.E. Spicknall and H.A. Sackeim, Repetitive transcranial magnetic stimulation to SMA worsens complex movements in Parkinson's disease, Clin Neurophysiol 112(2) (2001), 259-264.

[15] S.A. Brandt, C.J. Ploner, B.U. Meyer, S. Leistner and A. Villringer, Effects of repetitive transcranial magnetic stimulation over dorsolateral prefrontal and posterior parietal cortex on memory-guided saccades, Exp Brain Res 118(2) (1998), 197-204.

[16] J.P. Brasil-Neto, A. Cammarota, J. Valls-Sole, A. PascualLeone, M. Hallett and L.G. Cohen, Role of intracortical mechanisms in the late part of the silent period to transcranial stimulation of the human motor cortex, Acta Neurol Scand 92(5) (1995), 383-386.

[17] S.L. Bridgers and D.R. C., Transcranial magnetic stimulation: an assessment of cognitive and other cerebral effects, Neurology 39 (1989), 417-419.

[18] G.G. Cacciatore, Tailoring consent for innovative therapies, Am J Health Syst Pharm 52(6) (1995), 600-601.

[19] R. Chen, J. Classen, C. Gerloff, P. Celnik, E.M. Wassermann, M. Hallett et al., Depression of motor cortex excitability by low-frequency transcranial magnetic stimulation, Neurology 48(5) (1997), 1398-1403.

[20] R. Chen, C. Gerloff, J. Classen, E.M. Wassermann, M. Hallett and L.G. Cohen, Safety of different inter-train intervals for repetitive transcranial magnetic stimulation and recommendations for safe ranges of stimulation parameters, Electroencephalogr Clin Neurophysiol 105(6) (1997), 415-421.

[21] S. Chokroverty, W. Hening, D. Wright, T. Walczak, J. Goldberg, R. Burger et al., Magnetic brain stimulation: Safety studies, Electroencephalography and Clinical Neurophysiology 97 (1995), 36-42.

[22] H. Cohen, Z. Kaplan, M. Kotler, I. Kouperman, R. Moisa and N. Grisaru, Repetitive transcranial magnetic stimulation of the right dorsolateral prefrontal cortex in posttraumatic 
stress disorder: a double-blind, placebo-controlled study, Am J Psychiatry 161(3) (2004), 515-524.

[23] L.G. Cohen, P. Celnik, A. Pascual-Leone, B. Corwell, L. Falz, J. Dambrosia et al., Functional relevance of cross-modal plasticity in blind humans, Nature 389(6647) (1997), 180183.

[24] D.H. Cowan, Innovative therapy versus experimentation, Tort and Insurance Law Journal 21(4) (1986), 619-633.

[25] V. Crepel, J. Epsztein and Y. Ben-Ari, Ischemia induces short- and long-term remodeling of synaptic activity in the hippocampus, J Cell Mol Med 7(4) (2003), 401-407.

[26] J.E. Desmond, S.A. Chen, P.B. Shieh and A.L. Boxer, Right cerebellar single-pulse transcranial magnetic stimulation (tms) affects verbal working memory performance, Society for Neuroscience Abstracts 2003.

[27] V. Di Lazzaro, A. Oliviero, F. Pilato, E. Saturno, M. Dileone, M. Meglio et al., Effects of vagus nerve stimulation on cortical excitability in epileptic patients, Neurology 62(12) (2004), 2310-2312.

[28] E. Duzel, A. Hufnagel, C. Helmstaedter and C. Elger, Verbal working memory components can be selectively influenced by transcranial magnetic stimulation in patients with left temporal lobe epilepsy, Neuropsychologia 34(8) (1996), 775-783.

[29] P. Elad, T.A. Treves, M. Drory, R. Verchovsky, S. Klimovitsky, S. Ben-Laish et al., Demented patients' participation in a clinical trial: factors affecting the caregivers' decision, Int J Geriatr Psychiatry 15(4) (2000), 325-330.

[30] C.M. Epstein, J.J. Lah, K. Meador, J.D. Weissman, L.E. Gai$\tan$ and B. Dihenia, Optimum stimulus parameters for lateralized suppression of speech with magnetic brain stimulation, Neurology 47(6) (1996), 1590-1593.

[31] P. Ferguson, Patients' experiences and views of clinical trials, Med Law 20(2) (2001), 143-152.

[32] G.S. Figiel, C. Epstein, W.M. McDonald, J. Amazon-Leece, L. Figiel, A. Saldivia et al., The use of rapid-rate transcranial magnetic stimulation (rTMS) in refractory depressed patients, J Neuropsychiatry Clin Neurosci 10(1) (1998), 20-25.

[33] S.S. Flitman, J. Grafman, E.M. Wassermann, V. Cooper, J. O'Grady, A. Pascual-Leone et al., Linguistic processing during repetitive transcranial magnetic stimulation, Neurology 50(1) (1998), 175-181.

[34] M.A. Garvey, K.J. Kaczynski, D.A. Becker and J.J. Bartko, Subjective reactions of children to single-pulse transcranial magnetic stimulation, J Child Neurol 16(12) (2001), 891894.

[35] B. Gaymard, C. Pierrot-Deseilligny and S. Rivaud, Impairment of sequences of memory-guided saccades after supplementary motor area lesions, Ann Neurol 28(5) (1990), 622626.

[36] V. Geller, N. Grisaru, J.M. Abarbanel, T. Lemberg and R.H. Belmaker, Slow magnetic stimulation of prefrontal cortex in depression and schizophrenia, Prog Neuropsychopharmacol Biol Psychiatry 21(1) (1997), 105-110.

[37] M.S. George, D. Avery, Z. Nahas, M. Molloy, N.C. Oliver, S.C. Risch et al., rTMS studies of mood and emotion, Electroencephalogr Clin Neurophysiol Suppl 51 (1999), 304314.

[38] M.S. George, F.R. Sallee, Z. Nahas, N.C. Oliver and E.M. Wassermann, Transcranial magnetic stimulation (TMS) as a research tool in Tourette syndrome and related disorders, $A d v$ Neurol 85 (20010, 225-235.

[39] M.S. George, E.M. Wassermann, W.A. Williams, J. Steppel, A. Pascual-Leone, P. Basser et al., Changes in mood and hormone levels after rapid-rate transcranial magnetic stimulation (rTMS) of the prefrontal cortex, J Neuropsychiatry Clin Neurosci 8(2) (1996), 172-180.

[40] D.L. Gilbert, M.A. Garvey, A.S. Bansal, T. Lipps, J. Zhang and E.M. Wassermann, Should transcranial magnetic stimulation research in children be considered minimal risk? Clin Neurophysiol 115(8) (2004), 1730-1739.

[41] A. Gironell, J. Kulisevsky, J. Lorenzo, M. Barbanoj and B. Pascual, Low frequency repetitive transcranial magnetic stimulation of the cerebellum in patients with essential tremor: A double-blind, cross-over, randomized, placebocontrolled study, Neurology 54(7 Supp. 3) (2000), A116A117.

[42] J. Grafman, A. Pascual-Leone, D. Alway, P. Nichelli, E. Gomez-Tortosa and M. Hallett, Induction of a recall deficit by rapid-rate transcranial magnetic stimulation, Neuroreport 5(9) (1994), 1157-1160.

[43] R.M. Green, A. Pascual-Leone and E.M. Wassermann, Ethical guidelines for rTMS research, IRB 19 (1997), 1-7.

[44] B.D. Greenberg, M.S. George, J.D. Martin, J. Benjamin, T.E. Schlaepfer, M. Altemus et al., Effect of prefrontal repetitive transcranial magnetic stimulation in obsessive-compulsive disorder: a preliminary study, Am J Psychiatry 154(6) (1997), 867-869.

[45] N. Grisaru, M. Amir, H. Cohen and Z. Kaplan, Effect of transcranial magnetic stimulation in posttraumatic stress disorder: a preliminary study, Biol Psychiatry 44(1) (1998), 52-55.

[46] G.J. Harry and C. Lefebvre d'Hellencourt, Dentate gyrus: alterations that occur with hippocampal injury, Neurotoxicology 24(3) (2003), 343-356.

[47] R.E. Hoffman, K.A. Hawkins, R. Gueorguieva, N.N. Boutros, F. Rachid, K. Carroll et al., Transcranial magnetic stimulation of left temporoparietal cortex and medicationresistant auditory hallucinations, Arch Gen Psychiatry 60(1) (2003), 49-56.

[48] G. Hoflich, S. Kasper, A. Hufnagel, S. Ruhrmann and H.J. Moller, Application of transcranial magnetic stimulation in treatment of drug-resistant major depression: a report of two cases, Human Psychopharmacology 8 (1993), 361-365.

[49] M.M. Holi, M. Eronen, K. Toivonen, P. Toivonen, M. Marttunen and $\mathrm{H}$. Naukkarinen, Left prefrontal repetitive transcranial magnetic stimulation in schizophrenia, Schizophr Bull 30(2) (2004), 429-434.

[50] J.R. Hotson and S. Anand, The selectivity and timing of motion processing in human temporo-parieto-occipital cortex: A transcranial magnetic stimulation study, Neuropsychologia 37 (1998), 169-179.

[51] J.R. Hotson, D. Braun, W. Herzberg and B. D., Transcranial magnetic stimulation of extrastriate cortex degrades human motion direction discrimination, Vision Research 34 (1994), 2115-2123.

[52] T.J. Huber, U. Schneider and J. Rollnik, Gender differences in the effect of repetitive transcranial magnetic stimulation in schizophrenia, Psychiatry Res 120(1) (2003), 103-105.

[53] A. Hufnagel, D. Claus, C. Brunhoelzl and T. Sudhop, Shortterm memory: no evidence of effect of rapid-repetitive transcranial magnetic stimulation in healthy individuals, J Neurol 240(6) (1993), 373-376.

[54] J. Illes, Neuroethics in a new era of neuroimaging, AJNR Am J Neuroradiol 24(9) (2003), 1739-1741.

[55] J. Illes, M.P. Kirschen and J.D. Gabrieli, From neuroimaging to neuroethics, Nat Neurosci 6(3) (2003), 205. 
[56] J. Illes and E. Racine, Imaging or imagining: A neuroethics challenge informed by genetics, American Journal of Bioethics (In Press).

[57] J. Illes, A.C. Rosen, L. Huang, R.A. Goldstein, T.A. Raffin, G. Swan et al., Ethical consideration of incidental findings on adult brain MRI in research, Neurology 62(6) (2004), 888-890.

[58] A.R. Jonsen, M. Siegler and W.J. Winslade, Clinical Bioethics, (4th ed.), New York: McGraw-Hill, 1998.

[59] R. Kanayama, A.M. Bronstein, J. Shallo-Hoffmann, P. Rudge and M. Husain, Visually and memory guided saccades in a case of cerebellar saccadic dysmetria, J Neurol Neurosurg Psychiatry 57(9) (1994), 1081-1084.

[60] A. Kapstan, Y. Yaroslavsky, J. Applebaum, R.H. Belmaker and N. Grisaru, Right prefrontal TMS versus sham treatment of mania: a controlled study, Bipolar Disord 5(1) (2003), 36-39.

[61] J.P. Keenan and A. Pascual-Leone, Transcranial Magnetic Stimulation, Science \& Medicine 6 (1999), 8-17.

[62] N.M. King, Experimental treatment. Oxymoron or aspiration? Hastings Center Report 25(4) (1995), 6-15.

[63] E. Klein, I. Kreinin, A. Chistyakov, D. Koren, L. Mecz, S. Marmur et al., Therapeutic efficacy of right prefrontal slow repetitive transcranial magnetic stimulation in major depression: a double-blind controlled study, Arch Gen Psychiatry 56(4) (1999), 315-320.

[64] H.M. Kolbinger, G. Hoflich, A. Hufnagel, H.J. Moller and S. Kasper, Transcranial magnetic stimulation (TMS) in the treatment of major depression: a pilot study, Human Psychopharmacology 10 (1995), 305-310.

[65] L. Krain, J. Kimura, T. Yamada, J. Cadwell and S. Sakamaki, Consequences of cortical magnetoelectric stimulation, in: Magnetic Stimulation in Clinical Neurophysiology, S. Chokroverty, ed., Boston: Butterworths, 1990, pp. 157-163.

[66] L.O. Savant for a day, NY Times Magazine (22 June 2003), 2003:38.

[67] W.J. Levy, J. Oro, D. Tucker and S. Haghighi, Safety studies of electrical and magnetic stimulation for the production of motor evoked potentials, in: Magnetic Stimulation in Clinical Neurophysi, S. Chokroverty, ed., Boston: Butterworths, 1990, pp. 165-172.

[68] J. Li, J. Olson, S. Anand and J. Hotson, Rapid-rate transcranial magnetic stimulation of human frontal cortex evokes multistep saccades, Electroenceph Clin Neurophysiol 105 (1997), 246-254.

[69] S.H. Lisanby, L.H. Kinnunen and M.J. Crupain, Applications of TMS to therapy in psychiatry, J Clin Neurophysiol 19(4) (2002), 344-360.

[70] C.K. Loo, J.L. Taylor, S.C. Gandevia, B.N. McDarmont, P.B Mitchell and P.S. Sachdev, Transcranial magnetic stimulation (TMS) in controlled treatment studies: are some "sham" forms active? Biol Psychiatry 47(4) (2000), 325-331.

[71] J. Mally and T.W. Stone, Therapeutic and "dose-dependent" effect of repetitive microelectroshock induced by transcranial magnetic stimulation in Parkinson's disease, J Neurosci Res 57(6) (1999), 935-940.

[72] F. Manes, R. Jorge, M. Morcuende, T. Yamada, S. Paradiso and R.G. Robinson, A controlled study of repetitive transcranial magnetic stimulation as a treatment of depression in the elderly, Int Psychogeriatr 13(2) (2001), 225-231.

[73] J.L. Martin, M.J. Barbanoj, V. Perez and M. Sacristan, Transcranial magnetic stimulation for the treatment of obsessivecompulsive disorder, Cochrane Database Syst Rev 3 (2003), CD003387.
[74] U.D. McCann, T.A. Kimbrell, C.M. Morgan, T. Anderson, M. Geraci, B.E. Benson et al., Repetitive transcranial magnetic stimulation for posttraumatic stress disorder, Arch Gen Psychiatry 55(3) (1998), 276-279.

[75] W.M. McDonald and B.D. Greenberg, Electroconvulsive therapy in the treatment of neuropsychiatric conditions and transcranial magnetic stimulation as a pathophysiological probe in neuropsychiatry, Depress Anxiety 12(3) (2000), 135-143.

[76] A.M. McIntosh, D. Semple, K. Tasker, L.K. Harrison, D.G. Owens, E.C. Johnstone et al., Transcranial magnetic stimulation for auditory hallucinations in schizophrenia, Psychiatry Res 127(1-2) (2004), 9-17.

[77] D.L. Menkes, P. Bodnar, R.A. Ballesteros and M.R. Swenson, Right frontal lobe slow frequency repetitive transcranial magnetic stimulation (SF r-TMS) is an effective treatment for depression: a case-control pilot study of safety and efficacy, J Neurol Neurosurg Psychiatry 67(1) (1999), 113-115.

[78] D.L. Menkes and M. Gruenthal, Slow-frequency repetitive transcranial magnetic stimulation in a patient with focal cortical dysplasia, Epilepsia 41(2) (2000), 240-242.

[79] A. Miki, T. Nakajima, M. Takagi, M. Shirakashi and H. Abe, Detection of visual dysfunction in optic atrophy by functional magnetic resonance imaging during monocular visual stimulation, Am J Ophthalmol 122(3) (1996), 404415.

[80] G.H. Moll, S. Wischer, H. Heinrich, F. Tergau, W. Paulus and A. Rothenberger, Deficient motor control in children with tic disorder: evidence from transcranial magnetic stimulation, Neurosci Lett 272(1) (1999), 37-40.

[81] U.P. Mosimann, H.U. Fisch and T.E. Schlaepfer, Effectiveness of repetitive transcranial magnetic stimulation in the elderly depressed, ACNP Abstracts 2000.

[82] F.M. Mottaghy, A. Pascual-Leone, L.J. Kemna, R. Topper, H. Herzog, H.W. Muller-Gartner et al., Modulation of a brainbehavior relationship in verbal working memory by rTMS, Brain Res Cogn Brain Res 15(3) (2003), 241-249.

[83] B.R. Mull and M. Seyal, Transcranial magnetic stimulation of left prefrontal cortex impairs working memory, Clin Neurophysiol 112(9) (2001), 1672-1675.

[84] A. Munchau, B.R. Bloem, K.V. Thilo, M.R. Trimble, J.C. Rothwell and M.M. Robertson, Repetitive transcranial magnetic stimulation for Tourette syndrome, Neurology 59(11) (2002), 1789-1791.

[85] R.M. Muri, S. Rivaud, A.I. Vermersch, J.M. Leger and C. Pierrot-Deseilligny, Effects of transcranial magnetic stimulation over the region of the supplementary motor area during sequences of memory-guided saccades, Exp Brain Res 104(1) (1995), 163-166.

[86] R.M. Muri, A.I. Vermersch, S. Rivaud, B. Gaymard and C. Pierrot-Deseilligny, Effects of single-pulse transcranial magnetic stimulation over the prefrontal and posterior parietal cortices during memory-guided saccades in humans, $\mathrm{J} \mathrm{Neu}$ rophysiol 76(3) (1996), 2102-2106.

[87] Z. Nahas, F.A. Kozel, X. Li, B. Anderson and M.S. George, Left prefrontal transcranial magnetic stimulation (TMS) treatment of depression in bipolar affective disorder: a pilot study of acute safety and efficacy, Bipolar Disord 5(1) (2003), 40-47.

[88] Z. Nahas, M. Lomarev, D.R. Roberts, A. Shastri, J.P. Lorberbaum, C. Teneback et al., Unilateral left prefrontal transcranial magnetic stimulation (TMS) produces intensitydependent bilateral effects as measured by interleaved BOLD fMRI, Biol Psychiatry 50(9) (2001), 712-720. 
[89] A. Nezu, S. Kimura, S. Takeshita, H. Osaka and M. Tanaka, Magnetic stimulation of the corticospinal tracts in PelizaeusMerzbacher disease, Electroencephalogr Clin Neurophysiol 108(5) (1998), 446-448.

[90] L. Niehaus, K.T. Hoffmann, P. Grosse, S. Roricht and B.U. Meyer, MRI study of human brain exposed to high-dose repetitive magnetic stimulation of visual cortex, Neurology 54 (2000), 256-258.

[91] H. Oyachi and K. Ohtsuka, Transcranial magnetic stimulation of the posterior parietal cortex degrades accuracy of memory-guided saccades in humans, Invest Ophthalmol Vis Sci 36(7) (1995), 1441-1449.

[92] A. Pascual-Leone, J.R. Gates and A. Dhuna, Induction of speech arrest and counting errors with rapid-rate transcranial magnetic stimulation, Neurology 41 (1991), 697-702.

[93] A. Pascual-Leone, E. Gomez-Tortosa, J. Grafman, D. Alway, P. Nichelli and M. Hallett, Induction of visual extinction by rapid-rate transcranial magnetic stimulation of parietal lobe, Neurology 44(3 Pt 1) (1994), 494-498.

[94] A. Pascual-Leone, C.M. Houser, K. Reese, L.I. Shotland, J. Grafman, S. Sato et al., Safety of rapid-rate transcranial magnetic stimulation in normal volunteers, Electroencephalogr Clin Neurophysiol 89(2) (1993), 120-130.

[95] A. Pascual-Leone and F. Torres, Plasticity of the sensorimotor cortex representation of the reading finger in Braille readers, Brain 116(Pt 1) (1993), 39-52.

[96] A. Pascual-Leone, J. Valls-Sole, E.M. Wassermann and M. Hallett, Responses to rapid-rate transcranial magnetic stimulation of the human motor cortex, Brain 117 (1994), 847858.

[97] P.S. Sachdev, R. McBride, C.K. Loo, P.B. Mitchell, G.S. Malhi and V.M. Croker, Right versus left prefrontal transcranial magnetic stimulation for obsessive-compulsive disorder: a preliminary investigation, J Clin Psychiatry 62(12) (2001), 981-984.

[98] A.T. Sack and D.E. Linden, Combining transcranial magnetic stimulation and functional imaging in cognitive brain research: possibilities and limitations, Brain Res Brain Res Rev 43(1) (2003), 41-56.

[99] T. Satow, T. Mima, H. Hara, T. Oga, A. Ikeda, N. Hashimoto et al., Nausea as a complication of low-frequency repetitive transcranial magnetic stimulation of the posterior fossa, Clinical Neurophysiology 113(9) (2002), 1441-1443.

[100] C. Schonfeldt-Lecuona, G. Gron, H. Walter, N. Buchler, A. Wunderlich, M. Spitzer et al., Stereotaxic rTMS for the treatment of auditory hallucinations in schizophrenia, Neuroreport 15(10) (2004), 1669-1673.

[101] H. Shimamoto, H. Morimitsu, S. Sugita, K. Nakahara and M. Shigemori, Therapeutic effect of repetitive transcranial magnetic stimulation in Parkinson's disease, Rinsho Shinkeigaku 39(12) (1999), 1264-1267.
[102] H.R. Siebner, L. Lee and S. Bestmann, Interleaving TMS with functional MRI: now that it is technically feasible how should it be used? Clin Neurophysiol 114(11) (2003), 19971999.

[103] M.P. Szuba, J.P. O’Reardon, A.S. Rai, J. Snyder-Kastenberg, J.D. Amsterdam, D.R. Gettes et al., Acute mood and thyroid stimulating hormone effects of transcranial magnetic stimulation in major depression, Biol Psychiatry 50(1) (2001), 22-27.

[104] C.A. Tassinari, M. Cincotta, G. Zaccara and R. Michelucci, Transcranial magnetic stimulation and epilepsy, Clin Neurophysiol 114(5) (2003), 777-798.

[105] F. Tergau, U. Naumann, W. Paulus and B.J. Steinhoff, Lowfrequency repetitive transcranial magnetic stimulation improves intractable epilepsy, Lancet 353(9171) (1999), 2209.

[106] W.J. Triggs, K.J. McCoy, R. Greer, F. Rossi, D. Bowers, S. Kortenkamp et al., Effects of left frontal transcranial magnetic stimulation on depressed mood, cognition, and corticomotor threshold, Biol Psychiatry 45(11) (1999), 1440-1446.

[107] Y. Ugawa, Y. Terao, R. Hanajima, K. Sakai, T. Furubayashi, K. Machii et al., Magnetic stimulation over the cerebellum in patients with ataxia, Electroencephalogr Clin Neurophysiol 104(5) (1997), 453-458.

[108] T. Wagner, M. Gangitano, R. Romero, H. Theoret, M. Kobayashi, D. Anschel et al., Intracranial measurement of current densities induced by transcranial magnetic stimulation in the human brain, Neurosci Lett 354(2) (2004), 91-94.

[109] E.M. Wassermann, Risk and safety of repetitive transcranial magnetic stimulation: report and suggested guidelines from the International Workshop on the Safety of Repetitive Transcranial Magnetic Stimulation, June 5-7, 1996, Electroencephalogr Clin Neurophysiol 108(1) (1998), 1-16.

[110] E.M. Wassermann and S.H. Lisanby, Therapeutic application of repetitive transcranial magnetic stimulation: a review, Clin Neurophysiol 112(8) (2001), 1367-1377.

[111] E.M. Wassermann, B. Wang, T.A. Zeffiro, N. Sadato, A. Pascual-Leone, C. Toro et al., Locating the motor cortex on the MRI with transcranial magnetic stimulation and PET, Neuroimage 3(1) (1996), 1-9.

[112] H. Yamada, T. Tamaki, K. Wakano, A. Mikamia and E. Transfeldt, Effect of transcranial magnetic stimulation on cerebral function in a monkey model, Electroencephalography and Clinical Neurophysiology 97 (1995), 140-144.

[113] U. Ziemann, W. Paulus and A. Rothenberger, Decreased motor inhibition in Tourette's disorder: evidence from transcranial magnetic stimulation, Am J Psychiatry 154(9) (1997), 1277-1284. 


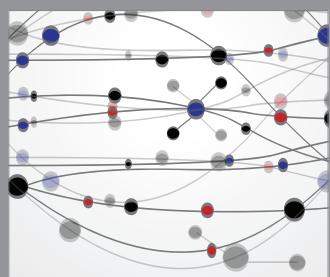

The Scientific World Journal
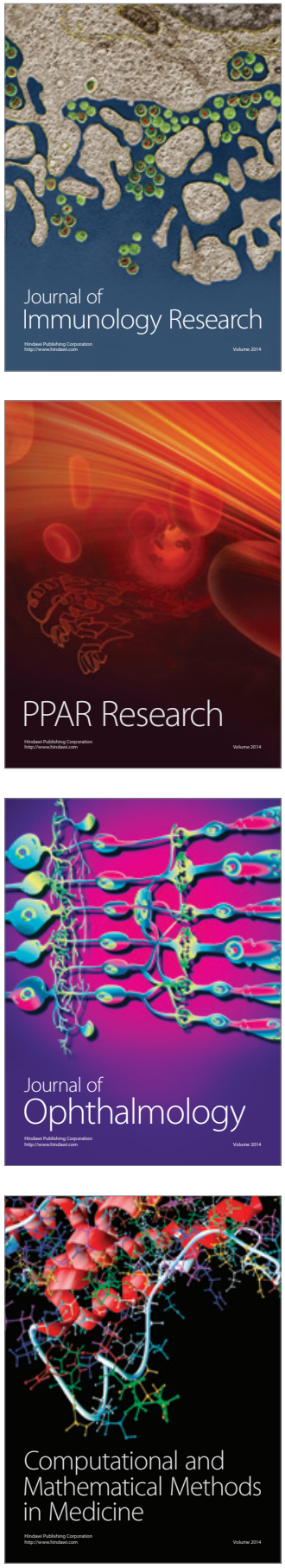

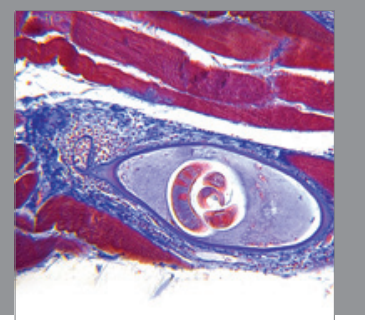

Gastroenterology

Research and Practice
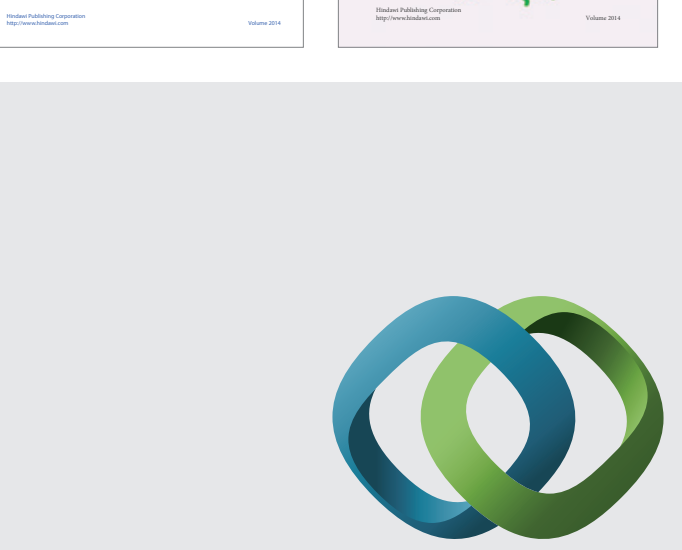

\section{Hindawi}

Submit your manuscripts at

http://www.hindawi.com
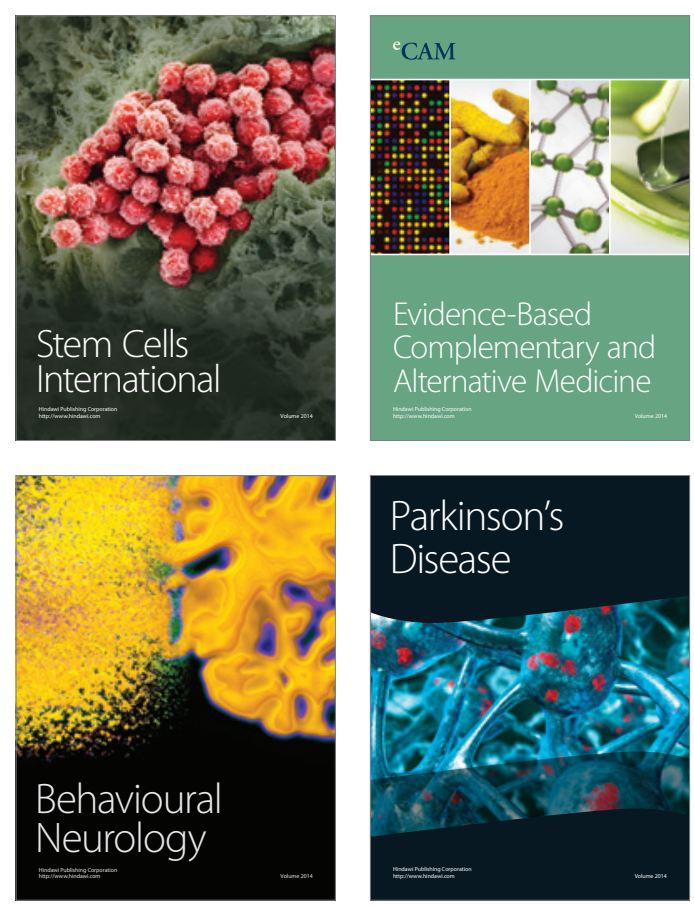

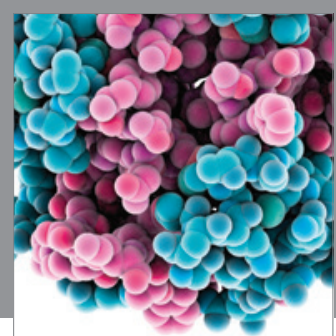

Journal of
Diabetes Research

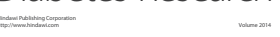

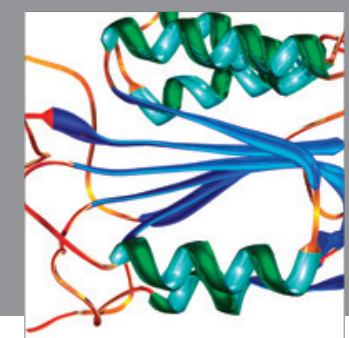

Disease Markers
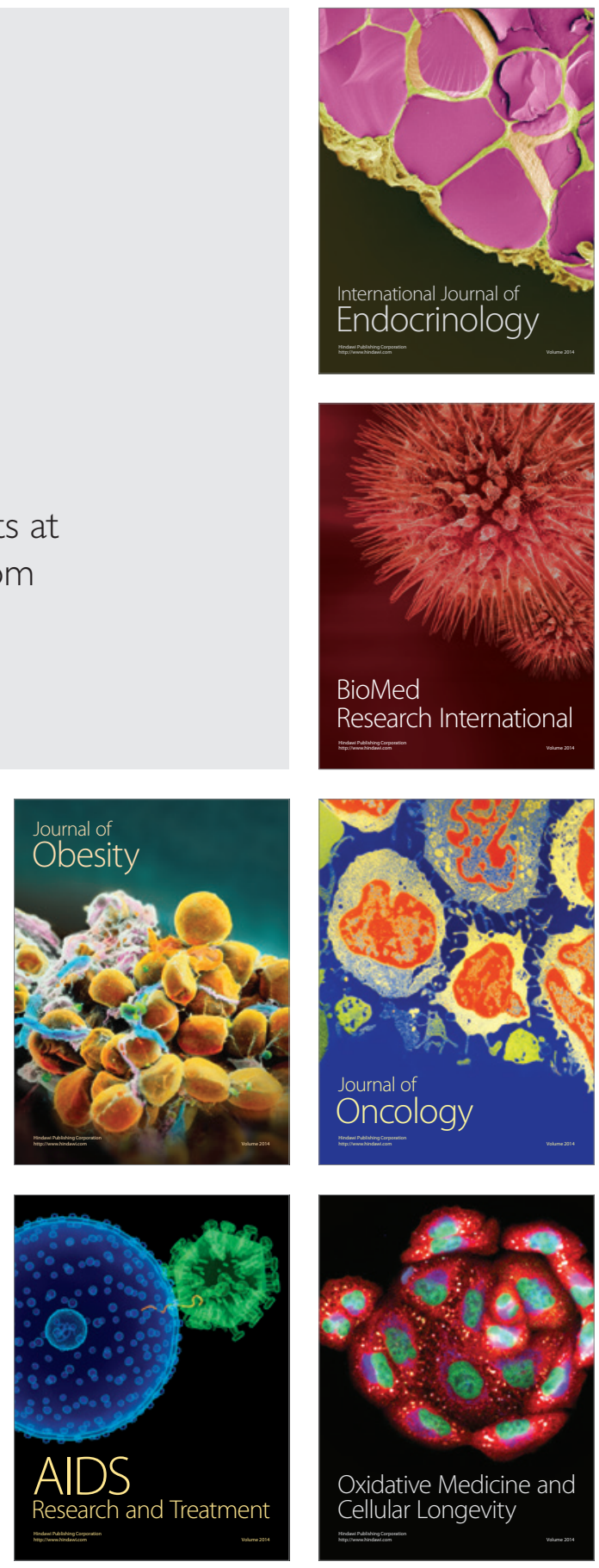